\title{
Statistical Monitoring and Optimization of Electrochemical Machining using Shewhart Charts and Response Surface Methodology
}

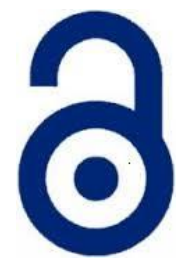 \\ Received: 17 April 2018 \\ Accepted: 10 May 2018 \\ Published: 30 June 2018 \\ Publisher: Deer Hill Publications \\ (C) 2018 The Author(s) \\ Creative Commons: CC BY 4.0
}

Ahmed Maged, Salah Haridy, Mohammad Shamsuzzaman, Imad Alsyouf and Roubi Zaied

\begin{abstract}
The response surface methodology (RSM) and Shewhart control charts have been widely used in manufacturing to reduce variation, improve quality and optimize the output. This article proposes an application of individuals \& moving range chart (I\&MR) and RSM in electrochemical machining. The Shewhart-type I\&MR control chart and RSM are combined together in an effective way to successfully guarantee the statistical control of the surface roughness $\left(R_{a}\right)$ of the items produced by wire electrochemical turning, and meanwhile optimize $R_{a}$ by exploring the optimal values of the machining parameters including applied voltage, wire feed rate, wire diameter, rotational speed and overlap distance. The conducted experiments reveal that the optimal values of the aforementioned factors are 23.67, $0.5,0.2,900$ and 0.02 , respectively. A second-order regression model is also developed to predict the output $\left(R_{a}\right)$ at different combinations of the input parameters. The developed regression model can predict the output values with a determination coefficient $\left(\mathrm{R}^{2}\right)$ of $96.9 \%$. The proposed combined scheme of Shewhart charts and RSM can be employed in other manufacturing processes and even in different service sectors to efficiently enhance the performance and reduce the cost.
\end{abstract}

Keywords: Electrochemical machining, surface roughness, control chart, response surface methodology, regression model, analysis of variance

\section{INTRODUCTION}

Distinct from conventional machining processes, non-traditional machining processes are capable of machining the highly alloyed materials irrespective their mechanical properties. Consequently, maximizing the need for the utilization of suitable techniques of non-traditional machining processes on different existing and newly developed materials (e.g. metals, non-metals, and composites, etc.) (Debnath, Kunar, Anasane, \& Bhattacharyya, 2017). Electrochemical Machining (ECM) is a non-traditional machining technique to shape metals by controlled anodic dissolution at extremely high current densities. The process evades mechanical stress applied to tool and workpiece, as well as it yields shiny surfaces without further finishing processes. Material hardness does not affect the process in any way. On the other hand, it can be used to achieve complex surfaces by changing the shape of the tool (Breitkopf \& Swider-Lyons, 2016). ECM process can be more economical if a conductive wire is used as a tool since it helps to prevent tool profiling. Using wire-tool allows cutting complex shapes with no need for large amount of power supplies (Qu, Ji, \& Zeng, 2014). Using wire-tool in ECM is known as Wire Electrochemical Machining (WECM). However, there are some difficulties while using in achieving the optimal parameters of machining process such as voltage applied $(v)$, feed rate $(f)$ and the diameter of the wire (d). The optimal machining parameters can enhance the key process characteristics such as the metal surface roughness $\left(R_{a}\right)$ and metal removal rate (MRR). Many articles have discussed the WECM (Kim, Na, Lee, Choi, \& Chu, 2005; Qu et al., 2014; Shin, Kim, \& Chu, 2008; Wang, Zeng, Liu, \& Zhu, 2012; Yamaguchi \& Natsu, 2017). Hofstede and Van Den Brekel (1970) suggested using a wire tool in Electrochemical Turning (ECT), which was later defined as Wire Electrochemical Turning (WECT). El-Taweel and Haridy (2014) experimentally determined the key factors affecting Metal Removal Rate (MRR) and investigated an efficient prediction model to maximize MRR in the WECT process.

A. Maged ${ }^{1, a}$ 瓜, S. Haridy1,2,b, M. Shamsuzzaman²,c, I. Alsyouf2,d and Roubi Zaied ${ }^{1,3, e}$

'Benha Faculty of Engineering, Benha University, Benha 13512, Egypt

2Department of Industrial Engineering and Engineering Management

University of Sharjah, PO Box 27272, Sharjah, United Arab Emirates

${ }^{3}$ Department of Industrial Engineering, Northern Border University, Arar 7322, Saudi Arabia

aE-mail: ahmed.maged@bhit.bu.edu.eg, bE-mail: sharidy@sharjah.ac.ae, cE-mail: mshamsuzzaman@sharjah.ac.ae dE-mail: ialsyouf@sharjah.ac.ae, eE-mail: rouby.nasr@bhit.bu.edu.eg

Reference: Maged et al. (2018). Statistical Monitoring and Optimization of Electrochemical Machining using Shewhart Charts and Response Surface Methodology. International Journal of Engineering Materials and Manufacture, 3(2), 68-77. 
Control chart (originally developed by Walter Shewhart in late 1920s) has played a key role in monitoring products' quality. The idea behind the developing of Shewhart control chart is that repeated measurements from a process will exhibit variation. In a stable process, the variation can be easily predicted and can be approximated by one of several statistical distributions. The sole purpose of control chart is to keep the process near the target value and within boundaries of natural variations (Benneyan, Lloyd, \& Plsek, 2003). On the other hand, response surface methodology (RSM) is a structured methodology of design of experiments (DoE) for systematically applying statistics to experimentations allowing the user to find relationships between the different input factors affecting the outputs. RSM typically involves setting up a combination of experiments, in which all relevant factors are varied systematically. These experiments are then analysed, allowing the user to find optimal parameters and the main factors affecting the results as well as identifying the interactions and synergies between factors if existed. It can be adopted whenever a phenomenon is to be investigated whether to gain more understanding or to achieve a better performance regardless of their background (Maged, Haridy, Kaytbay, \& Bhuiyan, In Press).

This study presents a combined scheme of RSM and Shewhart charts to obtain an adequate experimental procedure for investigating a reliable prediction model that relates input and output parameters of the WECT. The output parameter of interest in this case experiment is surface roughness. RSM is used to design and analyze all experiments. The output parameters are tested for statistical control using Individuals and moving range chart (I\&MR) control chart which is a Shewhart-type control chart. In addition, an optimization analysis is performed to locate the optimal values of the input parameters, accordingly minimizing the surface roughness. Minitab 17 is used for the statistical analysis held in this article.

\section{SHEWHART CONTROL CHARTS}

Statistical process control (SPC) techniques are adopted to monitor a process over time to detect variations in the performance (Woodall \& Montgomery, 1999). SPC methodologies include the employment of Shewhart control charts to detect assignable causes so that the corresponding root causes may be permanently removed. Control chart is the most commonly used tool in SPC (Oakland, 2007). The Shewhart control chart is one of the most popular statistical tools for monitoring a quality characteristic of interest. The popularity of the Shewhart control chart stems from its effectiveness and simplicity (Haridy, Maged, Kaytbay, \& Araby, 2017; Saleh, Mahmoud, Keefe, \& Woodall, 2015; Shamsuzzaman, Haridy, Alsyouf, \& Rahim, 2018).

In some situations, the sample size used for process control is $n=1$; that is, the sample consists of an individual unit (Skinner, Montgomery, \& Runger, 2003). For Examples, in occasions where automated inspection and measurement technology is used, and every single unit manufactured is inspected. In addition, where the production rate is very slow, a sample size of $n>1$ is not allowable. As well as, in situations where repeated measurements of a process differ only due to laboratory or inspection error, as in many chemical processes. In such situations, the I\&MR control chart is adequate. It uses the moving range of two successive observations to estimate the process variability. The moving range is defined as $M R_{i}=\left|\mathrm{X}_{\mathrm{i}}-\mathrm{X}_{\mathrm{i}-1}\right|$ an estimate of $\sigma$ is:

$$
\hat{\sigma}=\frac{\overline{M R}}{d_{2}}=\frac{\overline{M R}}{1.128}
$$

Because $d_{2}=1.128$ when two consecutive observations are used to calculate a moving range. The center line, and upper and lower control limits for a control chart for individuals are given by

$U C L=\bar{X}+3 \frac{\overline{M R}}{d_{2}}=\bar{X}+3 \frac{\overline{M R}}{1.128}, \quad C L=\bar{X}, \quad L C L=\bar{X}-3 \frac{\overline{M R}}{d_{2}}=\bar{X}-3 \frac{\overline{M R}}{1.128}$

\section{RESPONSE SURFACE METHODOLOCY}

Response surface methodology (RSM) is considered as a common tool in experimental data analytics. It is used when the influence of several input factors on a response variable are to be investigated by approximating complex functional relationships by "simple" linear or quadratic multivariate polynomial regression models, which are usually denoted as first or second order response surface models (Anderson-Cook, Borror, \& Montgomery, 2009; Myers, Montgomery, \& Anderson-Cook, 2009). The vast applications of RSM are in situations where several input variables potentially affect some performance measure or quality characteristic of the process, that is called as response.

Munda and Bhattacharyya (2008) proposed a general second order polynomial response surface model to evaluate the parametric influences on the various machining criteria as follows

$$
Y_{u}=b_{o}+\sum_{i=1}^{n} b_{i} X_{i u}+\sum_{i=1}^{n} b_{i i} X_{i u}^{2}+\sum_{j>i}^{n} b_{i j} X_{i u} X_{j u}+\varepsilon
$$

Where $\mathrm{Yu}$ is the corresponding response, $\mathrm{X}_{\mathrm{iu}}(1,2 \ldots \mathrm{n})$ are the coded levels of the $\mathrm{n}$ controlling machining parameters pertaining to $\mathrm{Yu}$, and $\varepsilon$ is the experimental error. The terms $\mathrm{bi}$, $\mathrm{b}_{\mathrm{ii}}$, and bij are the first and second-order regression coefficients. The second term of this polynomial equation is attributable to linear effect, whereas the third term corresponds to the higher-order effects; and the fourth term of the equation includes the interactive effects of the process parameters. Applying the least square technique, the values of these coefficients can be estimated by using 
the collected $\left(Y_{1}, Y_{2}, \ldots Y_{k}\right)$ through the $k$ design points (Munda \& Bhattacharyya, 2008). Mukhopadhyay and Khuri (2008) optimized response surface designs for multivariate generalized linear models. Anderson-Cook et al. (2009) discussed graphical methods used to evaluate design performance and their application on different RSM problems emphasizing how to use it to choose between competing designs.

Ahmad and Gilmour (2010) investigated design of experiments in case of missing observations and also, the robustness of subset designs was improved for multiple levels applying the minimax loss criterion. Khuri and Mukhopadhyay (2010) studied the various milestones in the development of response surface methodology. Drovandi et al. (2017) introduced a principled design of experiments approach to analyse big data. Many researchers usually use RSM as an optimization method. Campatelli, Lorenzini, and Scippa (2014) minimized the power consumption in milling process of carbon steel. Sarıkaya and Güllü (2014) analyzed and optimized the machining parameters of CNC turning process using Taguchi design and RSM. Thirugnanasambandham, Sivakumar, and Maran (2015) used RSM to optimize electrochemical treatment in food industry. Asiltürk, Neşeli, and Ince (2016) investigated the parameters affecting the surface roughness of medical material produced by CNC lathe machine using RSM and found that the radius of the machining tool tip is a key factor for optimizing it. Diel et al. (2016) increased the efficiency of energy usage in pulp and paper industry using RSM.

\section{EXPERIMENTAL SETUP}

All the required experiments are conducted on WECT test rig. The WET consists of three main parts, the mechanical components (e.g. gears, bolts, etc.), the electrical power driving system (e.g. motors) and the electrolyte flow control system. The test rig has three axes in order to achieve the motion in the $\mathrm{X}, \mathrm{Y}$, and Z-axes. The wire movement occurs in $\mathrm{X}$-axis direction parallel to the centre axis of the workpiece, while the workpiece rotates around the same axis. The X-axis screw is rotated by a stepper motor. A worm gear is used to reduce the rotational speed of the stepper motor. The stepper motor speed is controlled by the number of pulses from the microcontroller. For instance, the stepper motor of $1.8^{\circ}$ step will undergo a rotation of $1.8^{\circ}$ for each pulse received. So, a revolution of $360^{\circ}$ is performed by 200 pulses. The stepper motor speed and rotation direction controls the tool feed rate.

The workpiece is held inside a box by a rotatable chuck at one end, and by a centering tool at the other end. The workpiece rotating motion is controlled by a DC motor. The tool (i.e. wire) is fixed in a copper holder to resist corrosion. The wire is fixed by the nozzle and a tightening screw as indicated in Figure 1, allowing the electrolyte to flow and penetrate around it. Just before starting the WECT process, the initial position of the wire and workpiece is shown in Figure 2.

\subsection{Conditions and Measurements of Experiments}

A primitive WECT experimental set was successfully prepared to analyze the effect of the main machining input parameters on the machining performance characteristics of interest. Input parameters include applied voltage $(v)$, wire feed rate $(f)$, wire diameter $(d)$, rotational speed $(N)$ and overlap distance $(h)$. on the other hand, the machining performance characteristic is the surface roughness $(\mathrm{Ra})$. The experimental settings of WECT process parameters are depicted in Table 1. These conditions are chosen based on prior experiments and literature surveys (da Silva Neto, da Silva, \& da Silva, 2006; El-Taweel \& Haridy, 2014; Hofstede \& Van Den Brekel, 1970). Ra for each specimen was measured by a surface roughness tester. The final values shown in Table 3 are obtained by averaging four measurements.

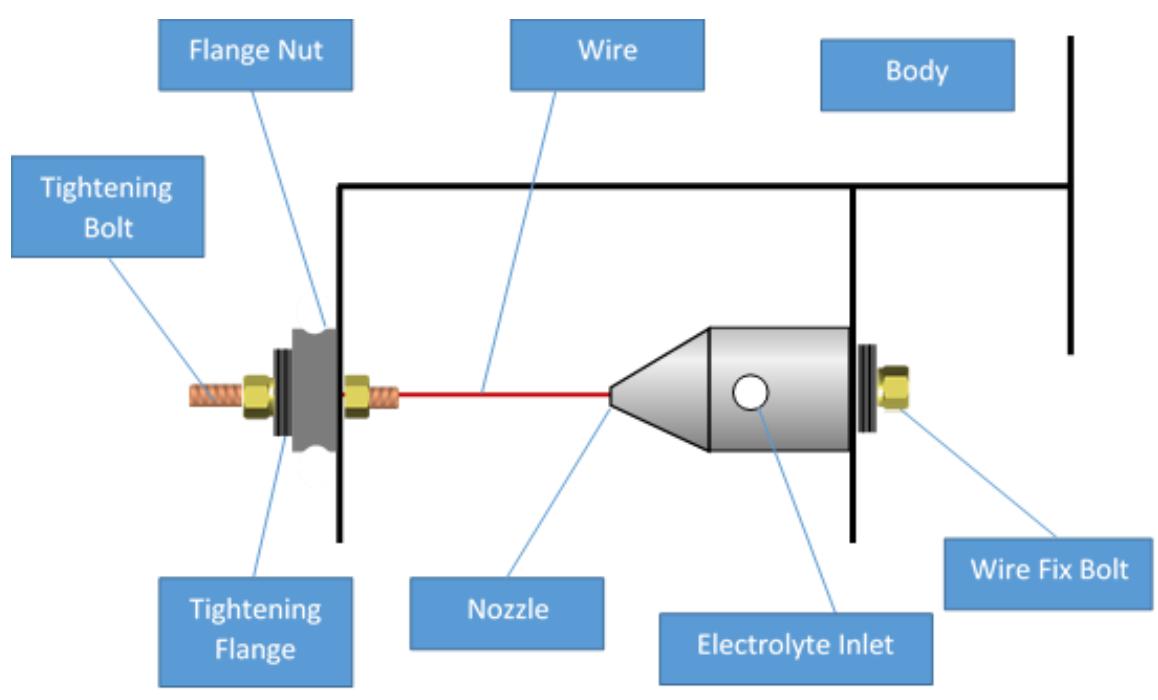

Figure 1: Tool holder model 


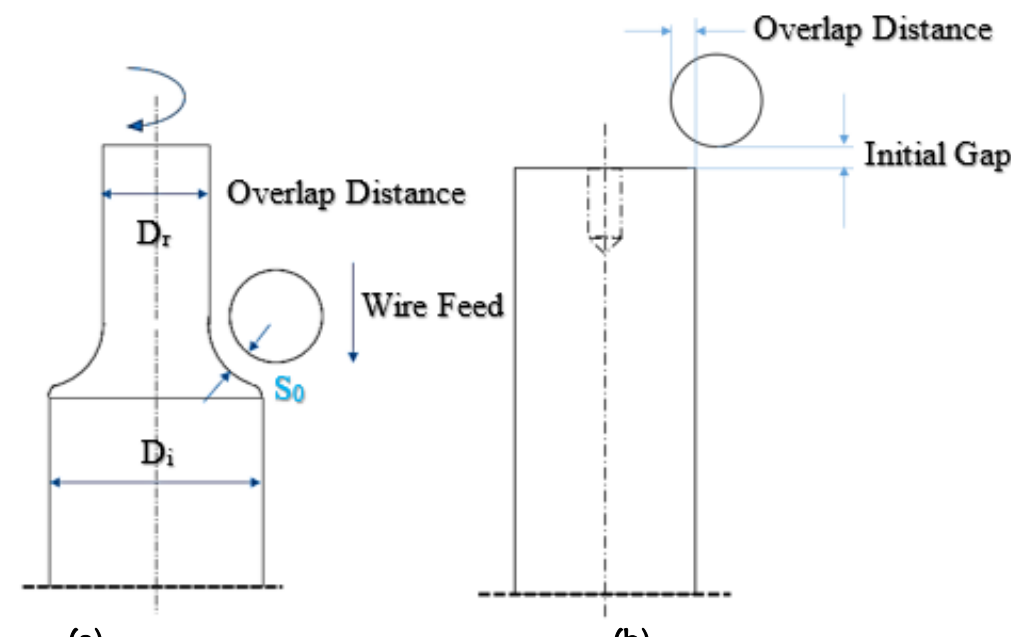

(a)

(b)

Figure 2: Various positions of wire and workpiece in WECM.

(a) Initial position of workpiece and wire and (b) machining of the workpiece.

Table 1: WECT working conditions

\begin{tabular}{ll}
\hline Working conditions & Description \\
\hline Workpiece material & Mild steel \\
Tool material & Brass \\
Applied voltage, $v$ & $10-40 \mathrm{~V}$ \\
Feed rate, $\mathrm{f}$ & $0.1-0.5 \mathrm{~mm} / \mathrm{min}$ \\
Wire diameter, $\mathrm{d}$ & $0.2-2 \mathrm{~mm}$ \\
Rotational speed, $\mathrm{N}$ & $300-900 \mathrm{rpm}$ \\
Overlap distance, $\mathrm{h}$ & $0.02-0.06 \mathrm{~mm}$ \\
Electrolyte type & $\mathrm{NaCl}$ \\
Electrolyte concentration & $250 \mathrm{~g} / \mathrm{l}$ \\
Electrolyte flow rate & $15 \mathrm{l} / \mathrm{min}$ \\
Initial frontal gap & $1 \mathrm{~mm}$ \\
Nozzle diameter & $6 \mathrm{~mm}$ \\
Machining distance & $11 \mathrm{~mm}$ \\
\hline
\end{tabular}

\section{IMPLEMENTATION AND DISCUSSIONS}

The implementation of the combined scheme of RSM and Shewhart charts is briefed below:

1. The values of the input parameters are defined using RSM.

2. The experiments are held using the generated values and their corresponding outputs are obtained.

3. Shewhart control chart is used to assess the process control on the output parameters.

4. Experiments are considered reliable for investigating a prediction model and optimality search, if the output parameters are in statistical control.

5. Experiments are considered invalid if the output parameters are not in statistical control. Assignable causes, which led to the non-statistical control or change the range of the input parameters, should be eliminated and a new set of input values has to be generated.

\subsection{Generating Input and Output Parameters}

Experimental runs are conducted on the test rig and responses are obtained. The input parameters of the real and coded values are listed in Table 2 . The design matrix used to hold the experiments and the corresponding output $R_{a}$ are illustrated in Table 3. 
Table 2: DoE factors levels in WECT

\begin{tabular}{llllll}
\hline Input Parameter & \multicolumn{5}{c}{ Levels } \\
\cline { 2 - 6 } & -2 & -1 & 0 & +1 & +2 \\
\hline Applied voltage $(\mathrm{v}), \mathrm{V}$ & 10 & 17.5 & 25 & 32.5 & 40 \\
Longitudinal feed rate (f), mm/min & 0.1 & 0.2 & 0.3 & 0.4 & 0.5 \\
Wire diameter (d), mm & 0.2 & 0.65 & 1.1 & 1.55 & 2 \\
Overlap distance (h), mm & 0.02 & 0.03 & 0.04 & 0.05 & 0.06 \\
Rotational speed (N), rpm & 300 & 450 & 600 & 750 & 900 \\
\hline
\end{tabular}

\subsection{Individuals Control Chart}

Individual - Moving Range (I\&MR) control chart (shown in Figure 3) is constructed to determine whether the surface roughness $\left(R_{a}\right)$ is in statistical control or not. It can be seen that all points are in statistical control; consequently the data can be used to build up a regression model.

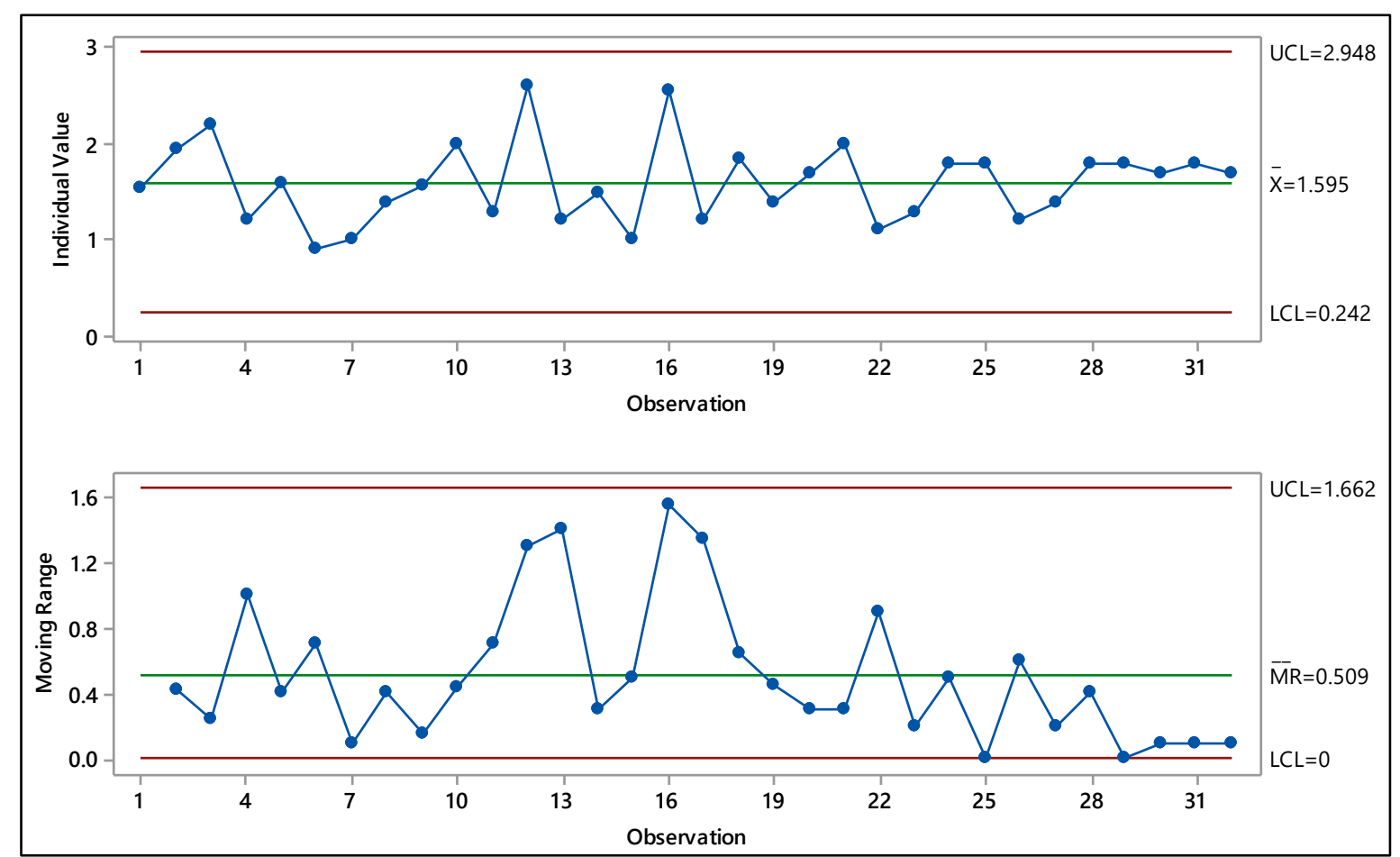

Figure 3: I\&MR chart for $R_{a}$

\subsection{Investigating the Prediction Models}

Prediction model is a mathematical model links the responses and the machining parameters. Using the relevant data listed in Table 3, the mathematical models of the real values of $R_{a}$ can be formulated as follows:

$$
\begin{aligned}
& R_{a}=11.57-0.1743 V-5.64 f-2.413 d-175.6 h-0.00707 N-0.000457 V^{2}-1.94 f^{2}-0.096 d^{2}-194 h^{2} \\
& +0.1492 V f+0.00722 V d+3.725 V h+2.9 \times 10^{(-5)} V N+0.681 f d+85.6 f h+10.69 d h+2.25 \times 10^{(-3)} d N+0.1212 h N
\end{aligned}
$$

The model is checked for adequacy by analysis of variance (ANOVA) as in Table 4 and a graphical presentation of predicted versus the experimental values is shown in Figure 4. It can be seen that the predicted values are quite close to the real ones. The model is now considered reliable for further predictions as long as they are within the specified range. 


\subsection{Main Effect Plot}

This plot (Figure 5) helps in distinguishing the significant factors from insignificant ones. Where there is an observable difference between the values of response at the high and low levels of a factor, this factor is contemplated as significant $(V, f, d, h$ and $N)$. It also demonstrates which level is to be maintained for the significant factors to minimize $\mathrm{R}_{\mathrm{a}}$. It can be seen that holding all the factors at high level will decrease the $\mathrm{R}_{\mathrm{a}}$.

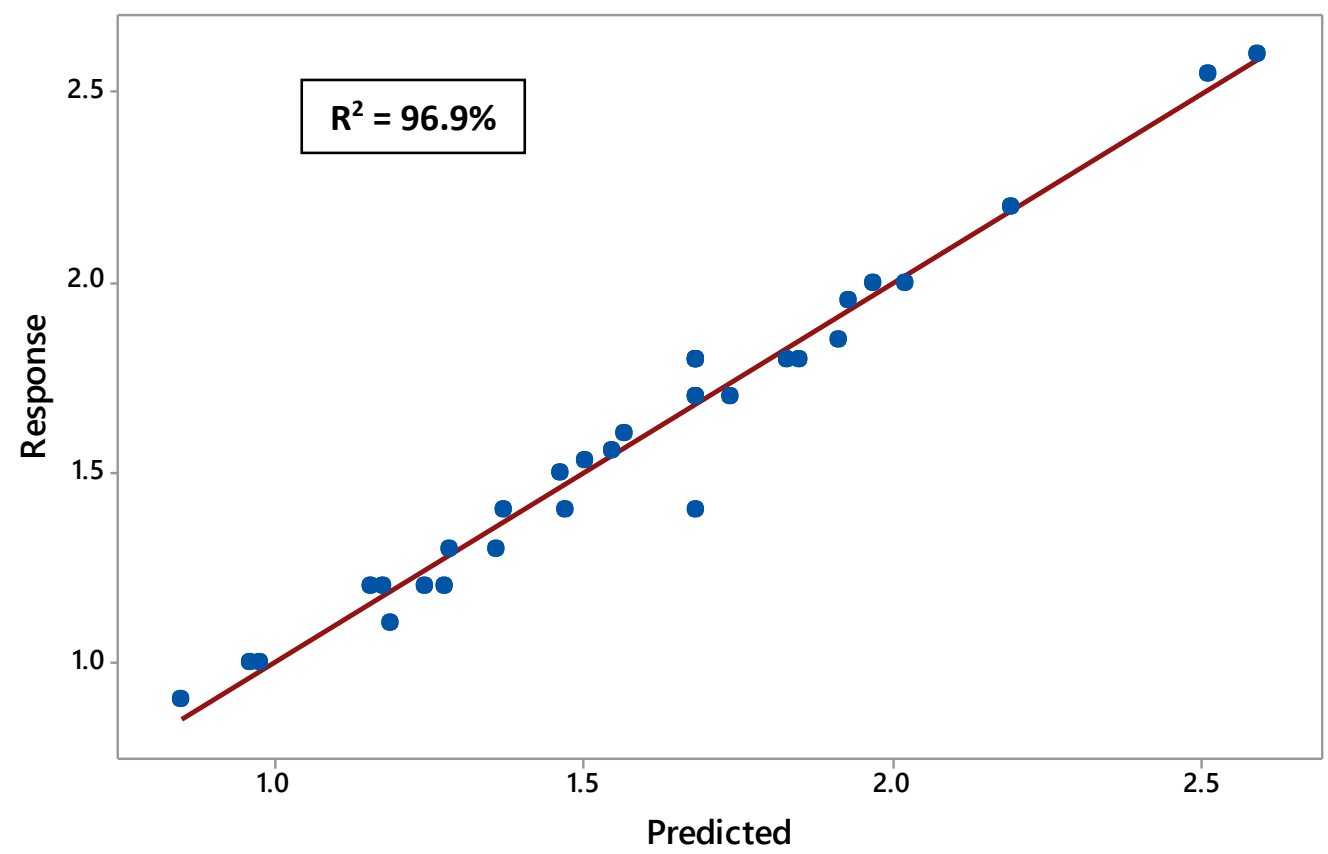

Figure 4: Predicted vs. real response values of $R_{a}$ surface roughness

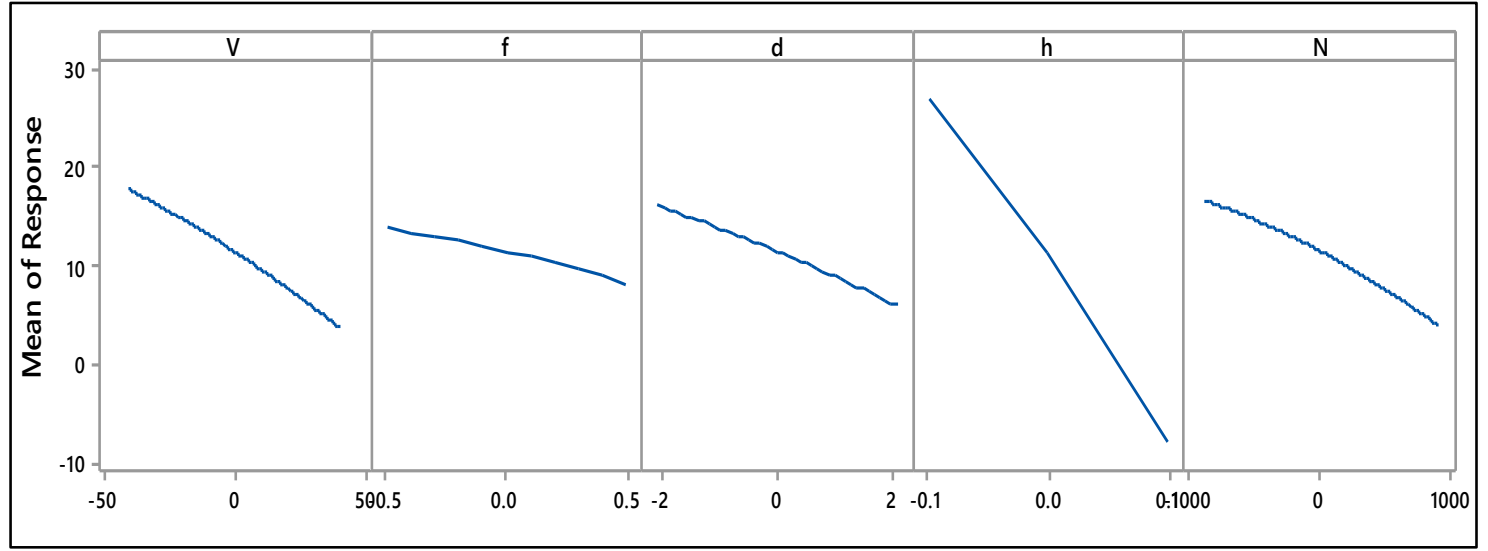

Figure 5: Main effect plot for $R_{a}$ surface roughness 
Table 3: Matrix of input variables and corresponding responses

\begin{tabular}{|c|c|c|c|c|c|c|c|c|c|c|c|}
\hline \multirow{3}{*}{$\begin{array}{l}\text { Exp. } \\
\text { No. }\end{array}$} & \multicolumn{10}{|c|}{ Input Parameters } & \multirow{3}{*}{$\begin{array}{l}\text { Surface } \\
\text { roughness } \\
\mathrm{R}_{\mathrm{a}}(\mu \mathrm{m})\end{array}$} \\
\hline & \multicolumn{2}{|c|}{ Applied voltage } & \multicolumn{2}{|c|}{ Feed rate } & \multicolumn{2}{|c|}{ Wire diameter } & \multicolumn{2}{|c|}{ Overlap distance } & \multicolumn{2}{|c|}{ Rotational speed } & \\
\hline & $\begin{array}{c}\text { Coded } \\
X_{1}\end{array}$ & $\begin{array}{c}\text { real } \\
V\end{array}$ & $\begin{array}{c}\text { Coded } \\
X_{2}\end{array}$ & $\begin{array}{c}\text { real } \\
\mathrm{mm} / \mathrm{min}\end{array}$ & $\begin{array}{c}\text { Coded } \\
x_{3}\end{array}$ & $\begin{array}{l}\text { real } \\
\mathrm{mm}\end{array}$ & $\begin{array}{c}\text { Coded } \\
X_{4}\end{array}$ & $\begin{array}{l}\text { real } \\
\mathrm{mm}\end{array}$ & $\mid \begin{array}{c}\text { Coded } \\
X_{5}\end{array}$ & $\begin{array}{l}\text { real } \\
\text { rpm }\end{array}$ & \\
\hline 1 & -1 & 17.5 & -1 & 0.2 & -1 & 0.65 & -1 & 0.03 & 1 & 750 & 1.53 \\
\hline 2 & 1 & 32.5 & -1 & 0.2 & -1 & 0.65 & -1 & 0.03 & -1 & 450 & 1.95 \\
\hline 3 & -1 & 17.5 & 1 & 0.4 & -1 & 0.65 & -1 & 0.03 & -1 & 450 & 2.2 \\
\hline 4 & 1 & 32.5 & 1 & 0.4 & -1 & 0.65 & -1 & 0.03 & 1 & 750 & 1.2 \\
\hline 5 & -1 & 17.5 & -1 & 0.2 & 1 & 1.55 & -1 & 0.03 & -1 & 450 & 1.6 \\
\hline 6 & 1 & 32.5 & -1 & 0.2 & 1 & 1.55 & -1 & 0.03 & 1 & 750 & 0.9 \\
\hline 7 & -1 & 17.5 & 1 & 0.4 & 1 & 1.55 & -1 & 0.03 & 1 & 750 & 1 \\
\hline 8 & 1 & 32.5 & 1 & 0.4 & 1 & 1.55 & -1 & 0.03 & -1 & 450 & 1.4 \\
\hline 9 & -1 & 17.5 & -1 & 0.2 & -1 & 0.65 & 1 & 0.05 & -1 & 450 & 1.56 \\
\hline 10 & 1 & 32.5 & -1 & 0.2 & -1 & 0.65 & 1 & 0.05 & 1 & 750 & 2 \\
\hline 11 & -1 & 17.5 & 1 & 0.4 & -1 & 0.65 & 1 & 0.05 & 1 & 750 & 1.3 \\
\hline 12 & 1 & 32.5 & 1 & 0.4 & -1 & 0.65 & 1 & 0.05 & -1 & 450 & 2.6 \\
\hline 13 & -1 & 17.5 & -1 & 0.2 & 1 & 1.55 & 1 & 0.05 & 1 & 750 & 1.2 \\
\hline 14 & 1 & 32.5 & -1 & 0.2 & 1 & 1.55 & 1 & 0.05 & -1 & 450 & 1.5 \\
\hline 15 & -1 & 17.5 & 1 & 0.4 & 1 & 1.55 & 1 & 0.05 & -1 & 450 & 1 \\
\hline 16 & 1 & 32.5 & 1 & 0.4 & 1 & 1.55 & 1 & 0.05 & 1 & 750 & 2.55 \\
\hline 17 & -2 & 10 & 0 & 0.3 & 0 & 1.1 & 0 & 0.04 & 0 & 600 & 1.2 \\
\hline 18 & 2 & 40 & 0 & 0.3 & 0 & 1.1 & 0 & 0.04 & 0 & 600 & 1.85 \\
\hline 19 & 0 & 25 & -2 & 0.1 & 0 & 1.1 & 0 & 0.04 & 0 & 600 & 1.4 \\
\hline 20 & 0 & 25 & 2 & 0.5 & 0 & 1.1 & 0 & 0.04 & 0 & 600 & 1.7 \\
\hline 21 & 0 & 25 & 0 & 0.3 & -2 & 0.2 & 0 & 0.04 & 0 & 600 & 2 \\
\hline 22 & 0 & 25 & 0 & 0.3 & 2 & 2 & 0 & 0.04 & 0 & 600 & 1.1 \\
\hline 23 & 0 & 25 & 0 & 0.3 & 0 & 1.1 & -2 & 0.02 & 0 & 600 & 1.3 \\
\hline 24 & 0 & 25 & 0 & 0.3 & 0 & 1.1 & 2 & 0.06 & 0 & 600 & 1.8 \\
\hline 25 & 0 & 25 & 0 & 0.3 & 0 & 1.1 & 0 & 0.04 & -2 & 300 & 1.8 \\
\hline 26 & 0 & 25 & 0 & 0.3 & 0 & 1.1 & 0 & 0.04 & 2 & 900 & 1.2 \\
\hline 27 & 0 & 25 & 0 & 0.3 & 0 & 1.1 & 0 & 0.04 & 0 & 600 & 1.4 \\
\hline 28 & 0 & 25 & 0 & 0.3 & 0 & 1.1 & 0 & 0.04 & 0 & 600 & 1.8 \\
\hline 29 & 0 & 25 & 0 & 0.3 & 0 & 1.1 & 0 & 0.04 & 0 & 600 & 1.8 \\
\hline 30 & 0 & 25 & 0 & 0.3 & 0 & 1.1 & 0 & 0.04 & 0 & 600 & 1.7 \\
\hline 31 & 0 & 25 & 0 & 0.3 & 0 & 1.1 & 0 & 0.04 & 0 & 600 & 1.8 \\
\hline 32 & 0 & 25 & 0 & 0.3 & 0 & 1.1 & 0 & 0.04 & 0 & 600 & 1.7 \\
\hline
\end{tabular}


Table 4: ANOVA analysis in WECT process

\begin{tabular}{|c|c|c|c|c|c|}
\hline Source & DF & SS & MS & F-value & P-value \\
\hline Model & 20 & 5.24398 & 0.2622 & 17.04 & 0 \\
\hline Linear & 5 & 1.01147 & 0.20229 & 13.15 & 0 \\
\hline V & 1 & 0.38017 & 0.38017 & 24.71 & 0 \\
\hline$f$ & 1 & 0.07337 & 0.07337 & 4.77 & 0.052 \\
\hline $\mathrm{d}$ & 1 & 0.28674 & 0.28674 & 18.64 & 0.001 \\
\hline $\mathrm{h}$ & 1 & 0.63507 & 0.63507 & 41.28 & 0 \\
\hline $\mathrm{N}$ & 1 & 0.23174 & 0.23174 & 15.06 & 0.003 \\
\hline Square & 5 & 0.06311 & 0.01262 & 0.82 & 0.56 \\
\hline$V * V$ & 1 & 0.01935 & 0.01935 & 1.26 & 0.286 \\
\hline$f * f$ & 1 & 0.01108 & 0.01108 & 0.72 & 0.414 \\
\hline$d * d$ & 1 & 0.01108 & 0.01108 & 0.72 & 0.414 \\
\hline$h * h$ & 1 & 0.01108 & 0.01108 & 0.72 & 0.414 \\
\hline$N * N$ & 1 & 0.02991 & 0.02991 & 1.94 & 0.191 \\
\hline 2-Way Interaction & 10 & 2.54561 & 0.25456 & 16.55 & 0 \\
\hline$V * f$ & 1 & 0.20026 & 0.20026 & 13.02 & 0.004 \\
\hline$V * d$ & 1 & 0.00951 & 0.00951 & 0.62 & 0.448 \\
\hline$V * h$ & 1 & 1.24881 & 1.24881 & 81.18 & 0 \\
\hline$V * N$ & 1 & 0.01756 & 0.01756 & 1.14 & 0.308 \\
\hline$f * d$ & 1 & 0.01501 & 0.01501 & 0.98 & 0.345 \\
\hline$f * h$ & 1 & 0.11731 & 0.11731 & 7.63 & 0.019 \\
\hline$f * N$ & 1 & 0.00181 & 0.00181 & 0.12 & 0.738 \\
\hline$d * h$ & 1 & 0.03706 & 0.03706 & 2.41 & 0.149 \\
\hline$d * N$ & 1 & 0.36906 & 0.36906 & 23.99 & 0 \\
\hline$h * N$ & 1 & 0.52926 & 0.52926 & 34.4 & 0 \\
\hline Error & 11 & 0.16922 & 0.01538 & & \\
\hline Lack-of-Fit & 6 & 0.04922 & 0.0082 & 0.34 & 0.888 \\
\hline Pure Error & 5 & 0.12 & 0.024 & & \\
\hline Total & 31 & 5.4132 & & & \\
\hline
\end{tabular}

Table 5: Optimized input parameters in WECT

\begin{tabular}{lc}
\hline Parameter & Optimal value \\
\hline Applied voltage ( $), \mathrm{V}$ & 23.67 \\
Longitudinal feed rate (f), mm/min & 0.5 \\
Wire diameter (d), mm & 0.2 \\
Overlap distance ( h), mm & 0.02 \\
Rotational speed ( N ), rpm & 900 \\
\hline
\end{tabular}

\subsection{Optimality Search}

Another objective of RSM is to find the region where the output of interest reaches or is very close to the optimal value. The purpose of optimality search is to evaluate the input parameters within the experiment ranges for minimizing $\mathrm{R}_{\mathrm{a}}$. Optimality search is done using utility transfer function (Sait, Aravindan, \& Haq, 2009). Based on the results of this implementation, the optimal configurations for minimum surface roughness are as shown in Table 5. According to Eqn. 4, surface roughness at these configurations will be approximately zero.

\section{CONCLUSIONS}

Wire Electrochemical Machining (WECM) is a popular non-traditional machining process for machining artificial materials with high strength and hardness. However, it is not easy to identify the optimal values of the machining parameters, such as voltage, feed rate, rotational speed, wire diameter, and overlap distance of the machining process. The use of optimal values of the machining parameters can enhance the key process characteristics such as the workpiece surface roughness and minimize the machining cost. This article proposes a combined scheme of 
response surface methodology (RMS) and Individuals chart in order to identify the optimal parameters of the WECM process. The applicability of the proposed scheme is tested through a real experiment. The output of the experiment is considered as surface roughness. The RSM is used to scientifically design and analyze all the experiments. The statistical control of the output (i.e. surface roughness) is evaluated using I\&MR control chart. Then, a prediction model linking the response (surface roughness $R_{a}$ ) and the input parameters (voltage, feed rate, rotational speed, wire diameter, and overlap distance) is developed based on the statistically in-control output data as evident by the I\&MR chart. Finally, an optimization search is conducted to identify the optimal combination of the machining parameters, which results in minimizing the surface roughness. The held experiments reveal that factors $(V, f, d, h$ and $\mathrm{N})$ are considered significant and their optimal values are $(23.67,0.5,0.2,0.02,900)$, respectively. The developed regression model can predict the output values with a $\mathrm{R}^{2}=96.9 \%$. It can be concluded that the proposed combined scheme including RSM and Shewhart chart might be an effective technique to guarantee the statistical control identify the optimal parameters of the WECM process.

\section{REFERENCES}

1. Ahmad, T., \& Gilmour, S. G. (2010). Robustness of subset response surface designs to missing observations. Journal of Statistical Planning and Inference, 140(1), 92-103.

2. Anderson-Cook, C. M., Borror, C. M., \& Montgomery, D. C. (2009). Response surface design evaluation and comparison. Journal of Statistical Planning and Inference, 139(2), 629-641.

3. Asiltürk, i., Neşeli, S., \& Ince, M. A. (2016). Optimisation of parameters affecting surface roughness of Co28Cr6Mo medical material during CNC lathe machining by using the Taguchi and RSM methods. Measurement, 78, 120128.

4. Benneyan, J., Lloyd, R., \& Plsek, P. (2003). Statistical process control as a tool for research and healthcare improvement. Quality and Safety in Health Care, 12(6), 458-464.

5. Breitkopf, C., \& Swider-Lyons, K. (2016). Springer Handbook of Electrochemical Energy: Springer.

6. Campatelli, G., Lorenzini, L., \& Scippa, A. (2014). Optimization of process parameters using a Response Surface Method for minimizing power consumption in the milling of carbon steel. Journal of Cleaner Production, 66, 309-316.

7. da Silva Neto, J. C., da Silva, E. M., \& da Silva, M. B. (2006). Intervening variables in electrochemical machining. Journal of Materials Processing Technology, 179(1), 92-96.

8. Diel, C. L., Canevesi, R. L. S., Zempulski, D. A., Awadallak, J. A., Borba, C. E., Palú, F., \& Silva, E. A. (2016). Optimization of multiple-effect evaporation in the pulp and paper industry using response surface methodology. Applied Thermal Engineering, 95, 18-23.

9. Debnath, S., Kunar, S., Anasane, S., \& Bhattacharyya, B. (2017). Non-traditional Micromachining Processes: Opportunities and Challenges Non-traditional Micromachining Processes (pp. 1-59): Springer.

10. Drovandi, C. C., Holmes, C., McGree, J. M., Mengersen, K., Richardson, S., \& Ryan, E. G. (2017). Principles of experimental design for Big Data analysis. Statistical Science, 32(3), 385-404.

11. El-Taweel, T., \& Haridy, S. (2014). An application of fractional factorial design in wire electrochemical turning process. The International Journal of Advanced Manufacturing Technology, 75(5-8), 1207-1218.

12. Haridy, S., Maged, A., Kaytbay, S., \& Araby, S. (2017). Effect of sample size on the performance of Shewhart control charts. The International Journal of Advanced Manufacturing Technology, 90(1), 1177-1185. doi:10.1007/s00170-016-9412-8

13. Hofstede, A., \& Van Den Brekel, J. (1970). Some remarks on electrochemical turning. Annals of the CIRP, 18, 93106.

14. Khuri, A. I., \& Mukhopadhyay, S. (2010). Response surface methodology. Wiley Interdisciplinary Reviews: Computational Statistics, 2(2), 128-149.

15. Kim, B. H., Na, C., Lee, Y.-S., Choi, D., \& Chu, C. (2005). Micro electrochemical machining of 3D micro structure using dilute sulfuric acid. CIRP Annals-Manufacturing Technology, 54(1), 191-194.

16. Maged, A., Haridy, S., Kaytbay, S., \& Bhuiyan, N. (In Press). Continuous improvement of injection moulding using Six Sigma: case study. International Journal of Industrial and Systems Engineering.

17. Mukhopadhyay, S., \& Khuri, A. I. (2008). Optimization in a multivariate generalized linear model situation. Computational Statistics \& Data Analysis, 52(10), 4625-4634.

18. Munda, J., \& Bhattacharyya, B. (2008). Investigation into electrochemical micromachining (EMM) through response surface methodology based approach. The International Journal of Advanced Manufacturing Technology, 35(7), 821-832.

19. Myers, R. H., Montgomery, D. C., \& Anderson-Cook, C. (2009). Response Surface Methodology, Hoboken. New Jersey: John Wiley\&Sons, Inc, 2(0), 38-38.

20. Oakland, J. S. (2007). Statistical process control: Routledge.

21. Qu, N., Ji, H., \& Zeng, Y. (2014). Wire electrochemical machining using reciprocated traveling wire. The International Journal of Advanced Manufacturing Technology, 72(5-8), 677-683. 
22. Sait, A. N., Aravindan, S., \& Haq, A. N. (2009). Optimisation of machining parameters of glass-fibre-reinforced plastic (GFRP) pipes by desirability function analysis using Taguchi technique. The International Journal of Advanced Manufacturing Technology, 43(5-6), 581.

23. Saleh, N. A., Mahmoud, M. A., Keefe, M. J., \& Woodall, W. H. (2015). The difficulty in designing Shewhart X and $X$ control charts with estimated parameters. Journal of Quality Technology, 47(2), 127.

24. Sarıkaya, M., \& Güllü, A. (2014). Taguchi design and response surface methodology based analysis of machining parameters in CNC turning under MQL. Journal of Cleaner Production, 65, 604-616.

25. Shamsuzzaman, M., Haridy, S., Alsyouf, I., \& Rahim, A. (2018). Design of economic X chart for monitoring electric power loss through transmission and distribution system. Total Quality Management \& Business Excellence, 1-21. doi:10.1080/14783363.2018.1433028

26. Shin, H. S., Kim, B. H., \& Chu, C. N. (2008). Analysis of the side gap resulting from micro electrochemical machining with a tungsten wire and ultrashort voltage pulses. Journal of Micromechanics and Microengineering, 18(7), 075009.

27. Skinner, K. R., Montgomery, D. C., \& Runger, G. C. (2003). Process monitoring for multiple count data using generalized linear model-based control charts. International Journal of Production Research, 41(6), 1167-1180.

28. Thirugnanasambandham, K., Sivakumar, V., \& Maran, J. P. (2015). Response surface modelling and optimization of treatment of meat industry wastewater using electrochemical treatment method. Journal of the Taiwan Institute of Chemical Engineers, 46, 160-167.

29. Wang, S., Zeng, Y., Liu, Y., \& Zhu, D. (2012). Micro wire electrochemical machining with an axial electrolyte flow. The International Journal of Advanced Manufacturing Technology, 63(1-4), 25-32.

30. Woodall, W. H., \& Montgomery, D. C. (1999). Research issues and ideas in statistical process control. Journal of Quality Technology, 31(4), 376.

31. Yamaguchi, K., \& Natsu, W. (2017). Investigation of Influence of Low-level Voltage on Machining Characteristics in Pulse Wire ECM. International Journal of Electrical Machining, 22, 14. 